\section{SIMULATION AND PERFORMANCE OF LIQUID LEVEL CONTROLLERS FOR LINEAR TANK}

\author{
Qahtan A. Mahmooda*, Amer T. Nawafa, Shaho A. \\ Mohamedalib
}

aTikrit University, College of Petroleum \& Minerals Engineering, Chemical Engineering Department, IRAQ

bTikrit University, College of Petroleum \& Minerals Engineering, Petroleum and Gas Engineering Department, IRAQ
Article history

Received

19 September 2019

Received in revised form

22 March 2020

Accepted

12 April 2020

Published online

28 April 2020

*Corresponding author

Qahtan.adnan@tu.edu.iq

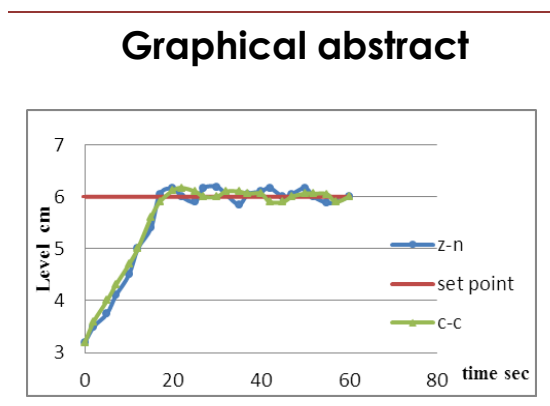

\begin{abstract}
Level control of liquid in a tank or any similar container is widely used in applications such as chemical and oil industrial processes. Control the level at desired value is very important. This paper studies the performance of P, PI, and PID controllers in controlling the level of a liquid. Mass balance is used to find mathematical model of water tank level. Ziegler-Nichol (Z-N) and Cohen-Coon (C-C) tuning methods are used to evaluate parameters of the controllers. The error indices such as Integral Absolute Error (IAE) and Integral Squared Error (ISE) are used to compare between performances of the controllers. MATLAB is used to test the control system performance and compare the results with real values. Both simulation and experimental results show that liquid level system can be controlled effectively by using Z-N tuning method. The result shows that the PI controller gives better performance in comparison with $\mathrm{P}$ and PID controller.
\end{abstract}

Keywords: Liquid level, Proportional Integral Derivative (PID) Control, Ziegler- Nichol (Z-N) and Cohen-Coon (C-C), MATLAB/SIMULINK

(C) 2020 Penerbit UTM Press. All rights reserved

\subsection{INTRODUCTION}

Controlling of liquid level in many processes is very important. The refinery process requires the crude oil to be pumped, stored in tanks then pumped to distillation column and stored in another tank. The level of the fluid in the tanks must be always controlled within the desired variables. Level control is widely used in process industries and wastewater treatment industries [1]. Simulation is used in initial system design to optimize controller gains, as well as in Model Based Design. Real-time operation of continuous simulation is used for operator training and off-line controller tuning. The software has to solve the mass and energy balance to find a stable operating point. Process simulation is widely used to find optimal conditions for an examined process [2]. In this paper the performance of $\mathrm{P}, \mathrm{PI}$ and PID controllers are investigated to control the liquid level in a tank by adjusting the inlet flowrate of the water to the tank. There are many ways to tuning PID controllers. In this paper the most famous of these methods, Ziegler-Nichol (Z-N) and Cohen-Coon (CC) were used to find controller parameters. The process simulation is carried out using MATLAB and the results are compared with results from real system.

\subsection{METHODOLOGY}

\subsection{Modeling of Liquid Level}

The mathematical modeling of liquid level in the tank is obtained using Mass balance. The scheme of the tank system is shown in Figure 1. Water is flowing 
to the tank at flowrate qin (lit/hr.) and the outlet flow is qo (lit/hr.). The cross-section area of tank is $\left(\mathrm{A} \mathrm{cm}^{2}\right)$. The height of the water level in the tank is represented by $\mathrm{h}(\mathrm{cm})$ which is controlled by adjusting the flowrate of the pump. Assuming the density of the inlet and outlet flowrate is constant and the tank has a uniform cross-sectional area [3].

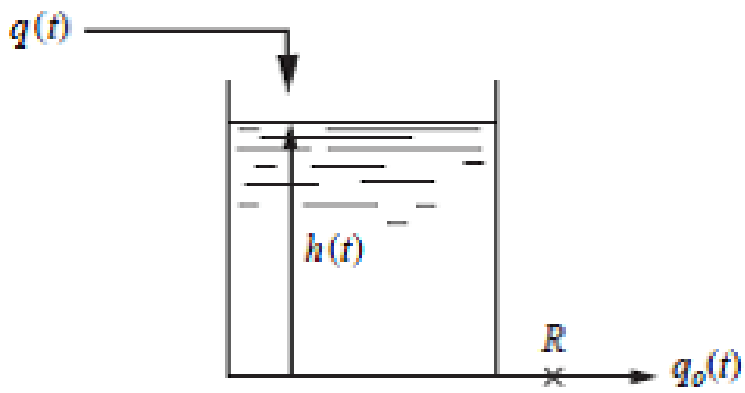

Figure 1 scheme of tank system

Amaterial balance around the SISO tank gives [3]. (Mass in) - (Mass out) $=$ (accumulation of mass in tank)

$$
\begin{aligned}
& \rho q_{i}-\rho q_{o=} \rho \frac{d V}{d t} \\
& q_{i}-q_{o=} A \frac{d h}{d t}
\end{aligned}
$$

The output volumetric flowrate of the tank is assumed follows nonlinear relationships (square root of height).

$$
q_{o}=c \sqrt{h}
$$

Where $\mathrm{c}$ is constant

Substitute equation (3) in equation (2) we get

$$
q_{i}-c \sqrt{h}=A \frac{d h}{d t}
$$

The inlet flowrate qin is a function of time. The outlet $q_{0}$ is modeled as a nonlinear function of the liquid level.

$$
\begin{gathered}
\sqrt{h}=\sqrt{h_{s}}+\frac{1}{2 \sqrt{h_{s}}}\left(h-h_{s}\right) \\
q_{i}-c\left[\sqrt{h_{s}}+\frac{1}{2 \sqrt{h_{s}}}\left(h-h_{s}\right)\right]=A \frac{d h}{d t} \\
q_{i s}-c\left[\sqrt{h_{s}}\right]=A \frac{d h_{s}}{d t} \quad \text { at s. } s h=h_{s}
\end{gathered}
$$

Subtracting equation (7) from equation (6) and rearrangement we get.

Assume $\frac{c}{2 \sqrt{h_{s}}}=\frac{1}{R}$

$$
Q_{i}-\frac{c}{2 \sqrt{h_{s}}} H=A \frac{d H}{d t}
$$

$$
R A \frac{d H}{d t}+H=R \cdot Q_{i}
$$

Taken Laplace for both sides of equation (9)

$$
\begin{aligned}
(\tau s+1) H_{(s)} & =R \cdot Q_{i_{(s)}} \\
G_{s y s}(s) & =\frac{H_{(s)}}{Q_{i_{(s)}}}=\frac{R}{(\tau s+1)}
\end{aligned}
$$

Table 1 Tank level parameters

\begin{tabular}{lcc}
\hline Parameters & Value & Units \\
\hline Area of tank (A) & 240.4 & $\mathrm{~cm}^{2}$ \\
Height $(\mathbf{H})$ & 7 & $\mathrm{~cm}$ \\
$\mathbf{R}$ & 0.472 & $\mathrm{sec} / \mathrm{cm}^{2}$ \\
\hline
\end{tabular}

The final transfer function of tank level is evaluated by using the values of the parameters shown in Table 1 as follows:

$$
\frac{H_{(s)}}{Q_{i_{(s)}}}=\frac{0.472}{113.4 S+1}
$$

\subsection{PID Controller}

PID control composed of three types of controllers $(P, I$ and $D)$ as shown in Figure $2[4,5]$.

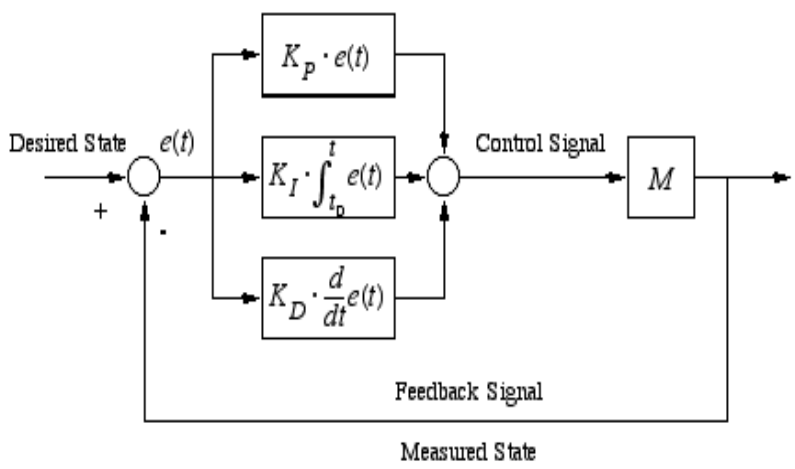

Figure 2 Schematic of PID Controller

\subsubsection{Proportional Control}

The proportional controller is used to reduce the error between the process output (measure value $\mathrm{MV}$ ) and the set point (SP), but cannot eliminate it. $[4,5]$.

$$
P_{\text {out }}=K_{P} \cdot e(t)
$$

The P-controller has one adjustable parameter, (the controller gain) $[5,6]$.

\subsubsection{Integral Control}

Integral control ultimately drives the error to zero by the proportional control $[4,7]$ 


$$
I_{\text {out }}=K_{I} \cdot \int_{0}^{t} e(t)
$$

The $\mathrm{Pl}$-controller has two adjustable parameters, (the gain) and (the integral time) [4, 8].

\subsubsection{Derivative Control}

The derivative controller acts upon the derivative of the error, so it is most active when the error is changing rapidly. The derivative controller is worked to decrease oscillation in output process $[4,9]$.

$$
D_{\text {out }}=K_{D} \cdot \frac{d}{d t} e(t)
$$

The PID- controller has three adjustable parameters, (the gain),(the integral time) and (the derivative time) $[4,7]$.

\subsubsection{Tunning of the Controller}

\section{Ziegler-Nichols}

The Ziegler-Nichole (Z-N) setting has been widely used as a benchmark for evaluating different tuning methods and control strategies [5, 6]. Ziegler-Nichole (Z-N) is applied in a closed loop system for tuning a PID controller as follows [5, 10-12]:

1. Reduce the (integral time) and (derivative time) to zero and using only P-controller.

2. Increase $K_{p}$ untill oscillations occur at critical value $\left(K_{p}=K_{c u}\right)$

3. Evaluate (ultimate gain $\mathrm{K}_{\mathrm{cu}}$ ) (ultimate period $\left.\mathrm{Pu}_{\mathrm{u}} \mathrm{ec}\right)$ as shown in Figure 3.

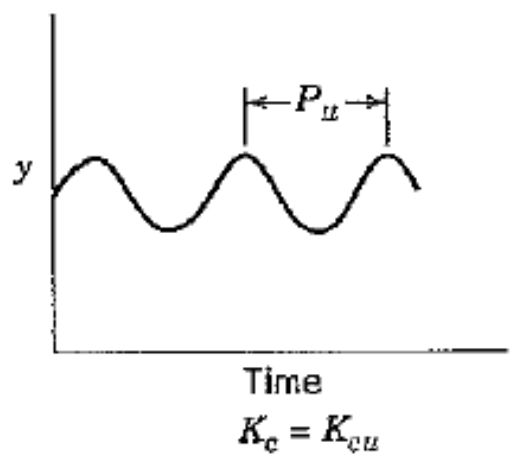

Figure 3 Experimental determination of the ultimate gain $\mathrm{K}_{\mathrm{cu}}$

The PID-controller parameters are now specified as showns in Table 2.
Table 2 Ziegler-Nichols setting based on the continuous cycling method

\begin{tabular}{cccc}
\hline $\begin{array}{c}\text { Ziegler- } \\
\text { Nichols }\end{array}$ & $\begin{array}{c}\mathrm{K}_{\mathrm{c}} \\
\text { (Proportional } \\
\text { gain) }\end{array}$ & $\begin{array}{c}\mathrm{T}_{\mathrm{I}} \\
\text { (integral } \\
\text { time) }\end{array}$ & $\begin{array}{c}\mathrm{T}_{\mathrm{D}} \\
\text { (derivative } \\
\text { time) }\end{array}$ \\
\hline $\begin{array}{c}\text { P- } \\
\text { controller } \\
\text { PI- }\end{array}$ & $\mathrm{K}_{\mathrm{cu}} / 2$ & --- & --- \\
$\begin{array}{c}\text { controller } \\
\text { PID- }\end{array}$ & $\mathrm{K}_{\mathrm{cu}} / 2.2$ & $\mathrm{Pu}_{\mathrm{u}} / 1.2$ & -- \\
controller & $\mathrm{K}_{\mathrm{cu}} / 1.7$ & $\mathrm{Pu} / 2$ & $\mathrm{Pu} / 8$ \\
\hline
\end{tabular}

\section{Cohen-Coon}

The Cohen and Coon tuning method is applied in the graphical construction as shown in Figure 4. (CC) method reduces the process reaction curve to first-order with the transport lag model given by equation (11) [4, 13-15].

$$
\mathrm{G}_{\mathrm{sys}}(\mathrm{s})=\frac{\mathrm{H}_{(\mathrm{s})}}{\mathrm{Q}_{\mathrm{i}(\mathrm{s})}}=\frac{\mathrm{Re}^{-\theta . s}}{(\tau \mathrm{s}+1)}
$$
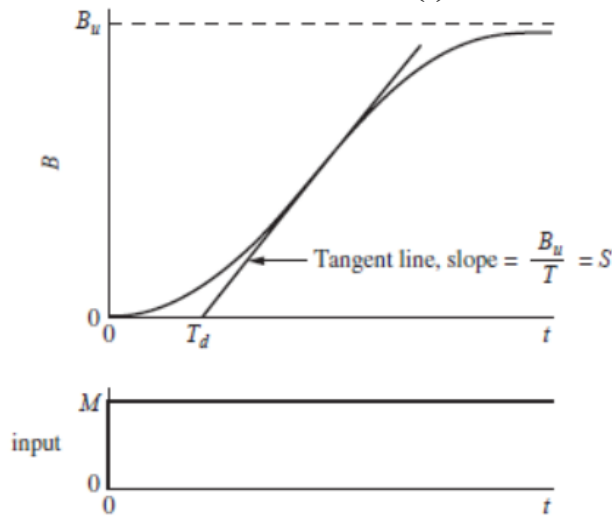

Figure 4 Typical process reaction curve showing graphical construction

The experimental procedure for (C-C) tuning method is quite simple and the control loop shown in Figure 5. When the process reaches to steadystate, the controller is changed to a manual mode. Then ( 3 to $5 \%$ ) step change in the controller output is introduced. The response of the system is called the process reaction curve $[5,16]$.

The parameters of PID-controller tuning by using (Cohen - Coon) open loop response are shown in Table 3. 


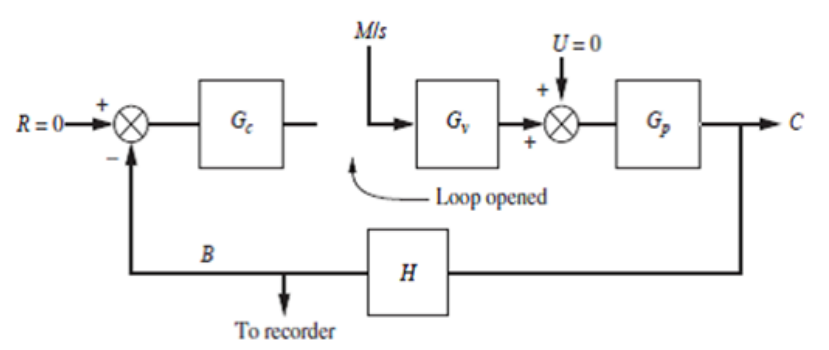

Figure 5 Control loop for process reaction curve method

Table 3 PID controller parameters by (Cohen-Coon) tuning

\begin{tabular}{cccc}
\hline Controller & $\mathbf{K}_{\mathbf{C}}$ & $\boldsymbol{\tau}_{\mathbf{I}}$ & $\boldsymbol{\tau}_{\mathbf{D}}$ \\
\hline $\mathbf{P}$ & $\frac{1}{\mathrm{~K}}\left[\frac{\tau}{\theta}+\frac{1}{3}\right]$ & \\
PI & $\frac{1}{\mathrm{~K}}\left[0.9 \frac{\tau}{\theta}+\frac{1}{12}\right]$ & $\theta\left(\frac{30+3 \frac{\theta}{\tau}}{9+20 \frac{\theta}{\tau}}\right)$ & \\
PID & $\frac{1}{\mathrm{~K}}\left[\frac{4}{3} \frac{\tau}{\theta}+\frac{1}{4}\right]$ & $\theta\left(\frac{32+6 \frac{\theta}{\tau}}{13+8 \frac{\theta}{\tau}}\right)$ & $\theta\left(\frac{4}{11+2 \frac{\theta}{\tau}}\right)$
\end{tabular}

\subsection{Simulation}

The simulation for the tank process system was created by using MATLAB Simulink software, and the block diagram is shown in Figure 6 [17-20]. The system simulation response is analyzed for change in the set point of the liquid level in the tank from (3 to $6 \%$ ) and responses recorded at a different controller and different controller tuning methods.

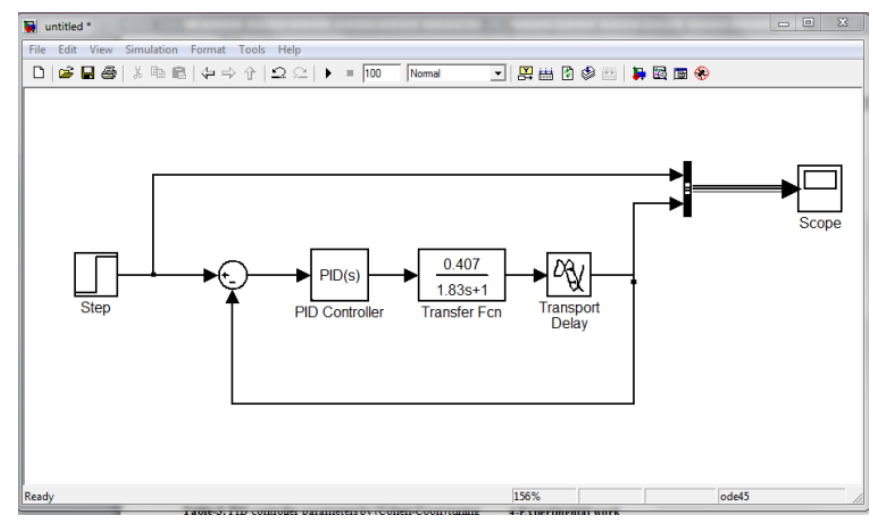

Figure 6 Simulink Block Diagram for Process Tank

\subsection{Experimental Work}

A five-liter cylindrical vessel made from glasses is used as a tank as shown in Figure 7. The pump is used to flowrate the water (0 to 200 lit/hr.) from the receiver to the tank. The flowrate is measured by using a rotameter on the discharge of the pump. The outlet flowrate is adjusted by using a hand valve between the tank and the receiver to circulate the water. The level transmitter is used to measure the level inside the tank and send a signal to the PID controller which is used to control the pump speed.

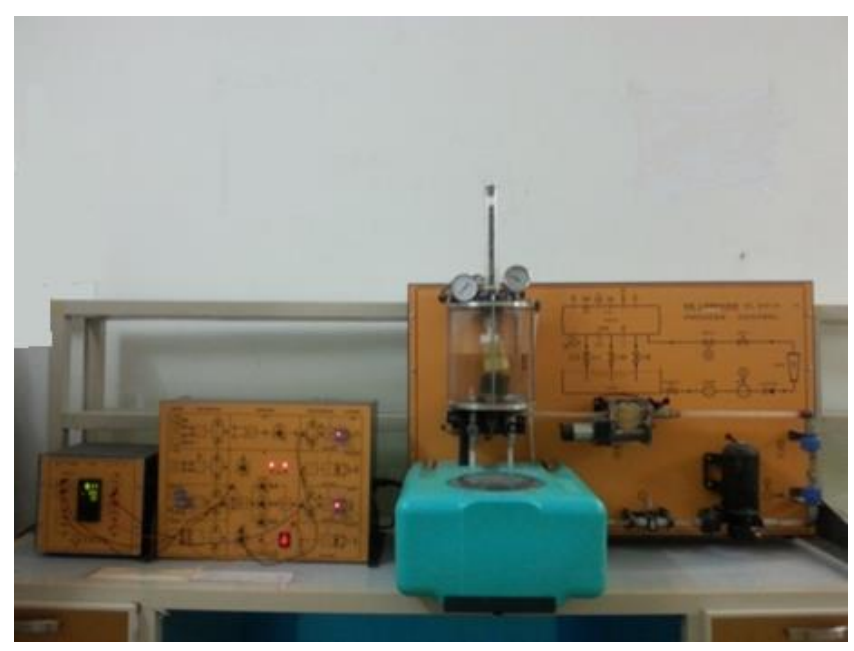

Figure 7 Experimental tank level control

\subsection{RESULTS AND DISCUSSION}

\subsection{Modeling of Liquid Level}

A step change (25 to $30 \%$ ) in the input flowrate to the process is done and the output response of the system is observed as shown in Figure 8. This procedure is called the (process reaction curve).

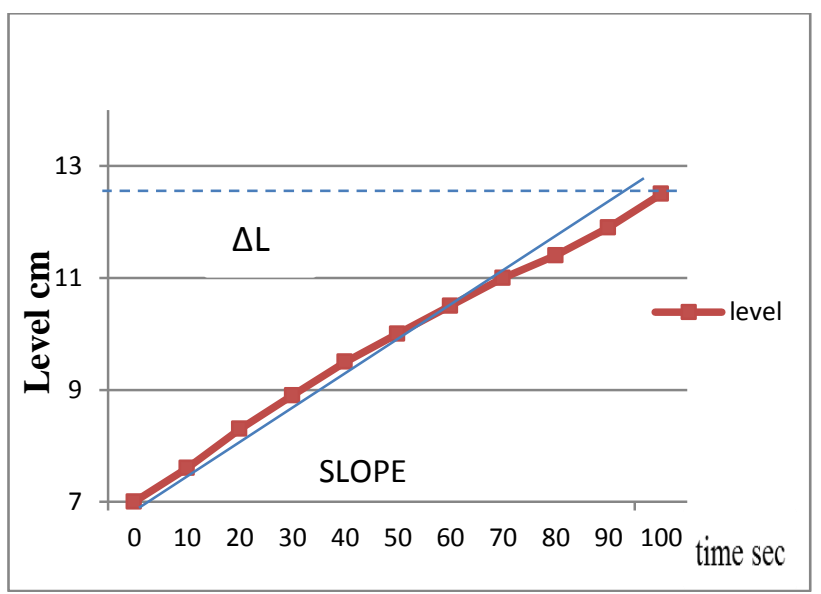

Figure 8 Tank level reaction curve for Cohen-Coon tuning

The dynamic model for liquid level is described by a (first order with dead time), as shown in Equation (11).

$$
\mathrm{G}_{\mathrm{sys}}(\mathrm{s})=\frac{\mathrm{H}_{(\mathrm{s})}}{\mathrm{Q}_{\mathrm{i}(\mathrm{s})}}=\frac{\mathrm{Re}^{-\theta . s}}{(\tau \mathrm{s}+1)}
$$


The parameters of analytical model, Equation (10) and experimental model, Equation (11) are calculated and summarized in Table 4.

Table 4 Parameters of transfer function of liquid level

\begin{tabular}{ccc}
\hline Parameters & Analytical & Experimental \\
\hline $\mathbf{R}$ sec $/ \mathbf{c m}^{2}$ & 0.472 & 0.407 \\
$\boldsymbol{T}$ second & 113.4 & 110 \\
$\boldsymbol{\theta}$ second & 0.5 & 3.5 \\
\hline
\end{tabular}

From the results, we see small differences in values between analytical and experimental model for the liquid level.

\section{2 (Ziegler-Nichols) and (Cohen-Coon) Methods}

(Z-N) Is used for closed loop response which made the system oscillate, and the values of ultimate gain and ultimate period are found to be as shown in Table 5.

Table 5 Parameters (Ziegler-Nichols) closed loop response

\begin{tabular}{cc}
\hline (Ultimate gain $\left.\mathbf{K}_{\mathrm{cu}}\right)$ & (Ultimate period $\mathbf{P}_{\mathrm{u}}$ )(sec) \\
\hline 12 & 10 \\
\hline
\end{tabular}

Cohen and Coon used the approximate model as shown in equation (11) and estimate the values (R, $\theta$ and $\tau$ ) as shown in Table 6.

Table 6 Parameters of (Cohen - Coon) approximate model

\begin{tabular}{ccc}
\hline $\left.\mathbf{R}\left[\mathbf{s e c} / \mathrm{cm}^{2}\right)\right]$ & $\boldsymbol{\tau}(\mathrm{sec})$ & $\boldsymbol{\theta}(\mathrm{sec})$ \\
\hline 0.407 & 110 & 3.5 \\
\hline
\end{tabular}

The values of PID-controller parameters calculated by applying both (Z-N) and (C-C) tuning methods are summarized in Table 7.

Table 7 Parameters of PID controller

\begin{tabular}{ccccccc}
\hline \multirow{2}{*}{ Controller } & \multicolumn{3}{c}{ Ziegler- Nichols } & \multicolumn{3}{c}{ Cohen-Coon } \\
\cline { 2 - 7 } & $\mathrm{K}_{\mathrm{c}}$ & $\tau_{\boldsymbol{I}}$ sec & $\boldsymbol{\tau}_{\boldsymbol{D}}$ sec & $\mathrm{K}_{\mathrm{c}}$ & $\boldsymbol{\tau}_{\boldsymbol{I}}$ sec & $\boldsymbol{\tau}_{\boldsymbol{D}}$ sec \\
\hline $\mathbf{P}$ & 6 & --- & --- & 78 & --- & --- \\
PI & 5.4 & 8.33 & -- & 69 & 7 & --- \\
PID & 7.2 & 5 & 1.25 & 98 & 8.5 & 1.27 \\
\hline
\end{tabular}

\subsection{Simulation Results}

Simulation results of (Z-N) and (C-C) methods are discussed in this section. Responses of $\mathrm{P}$ controller to step change in set point of liquid level from (3 to $6 \%$ ) has been shown in Figures 9 and 10. From the figures, we see the $\mathrm{P}$ controller with (Z-N) tuning is better than $(C-C)$ tuning method. Similarity, response of PI controller to step change in set point of liquid level from (3 to $6 \%$ ) has been shown in Figures 11 and 12. From the figures, we see the PI controller with (Z-N) tuning is better and have less oscillation in compare with (C-C) tuning method. Figures 13 and 14 show response of PID controller to step change in set point of liquid level from (3 to $6 \%$ ) and we see the PID controller have oscillation with (Z-N) and (CC) tuning method.

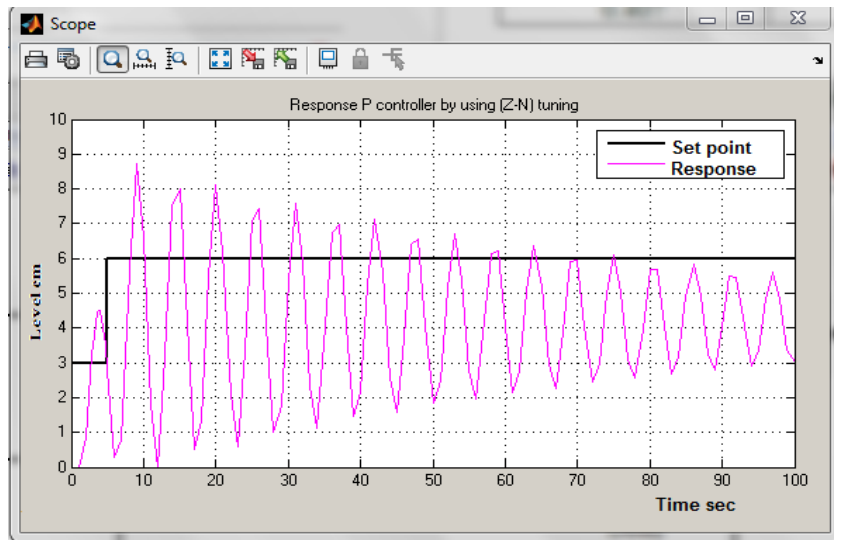

Figure 9 Simulation response of P-controller by using (Z-N) tuning

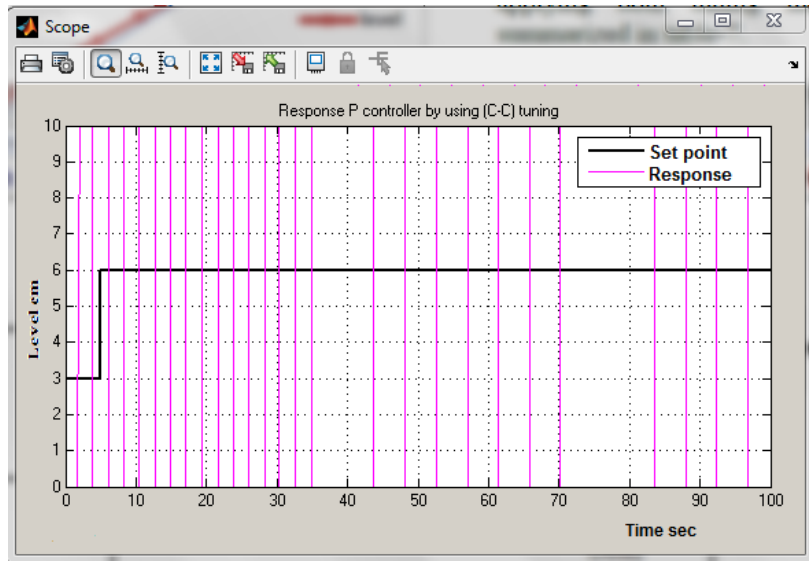

Figure 10 Simulation response of $\mathrm{P}$-controller by using (C-C) tuning

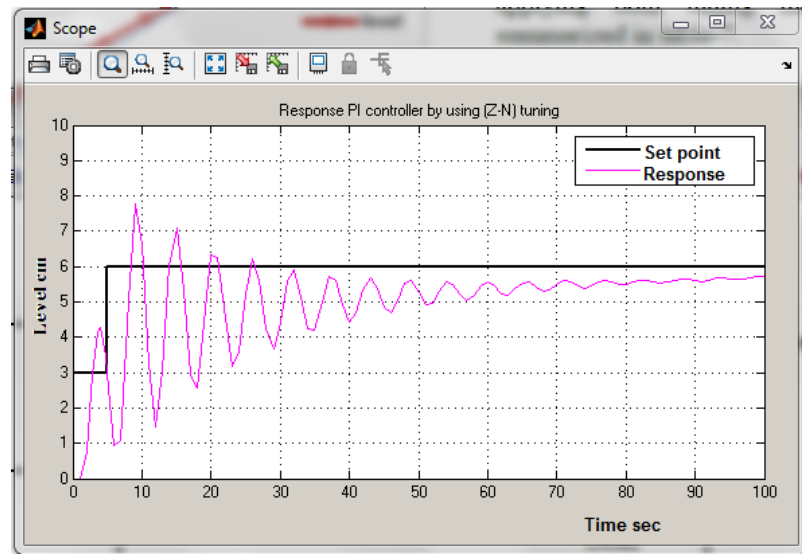

Figure 11 Simulation response of Pl-controller by using (Z-N) tuning 


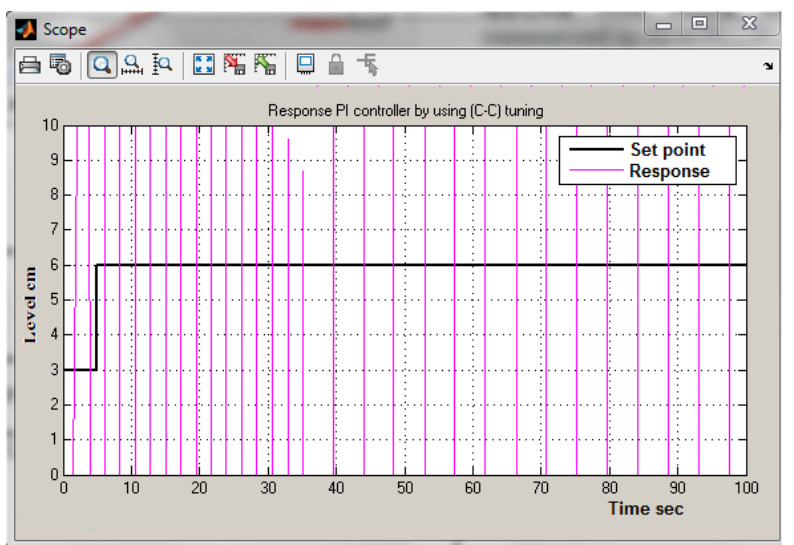

Figure 12 Simulation response of $\mathrm{Pl}$-controller by using (C-C) tuning

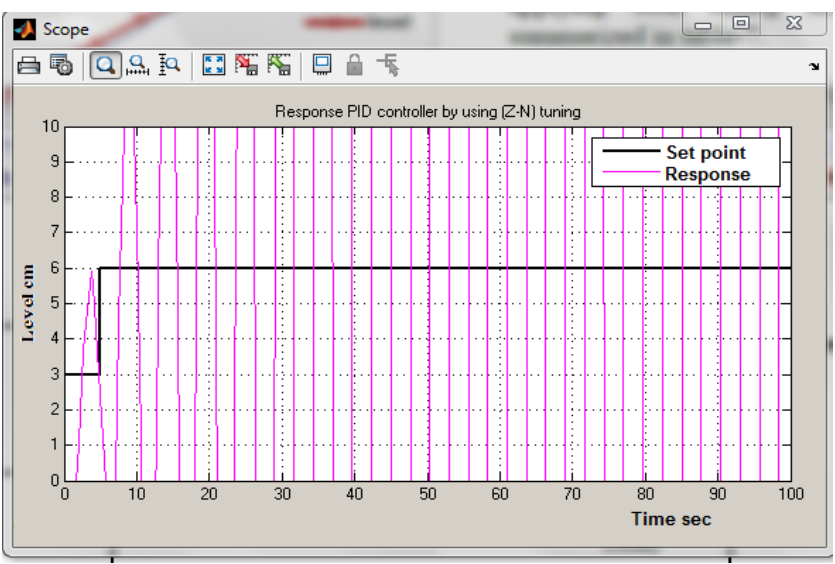

Figure 13 Simulation response of PID-controller by using (ZN) tuning

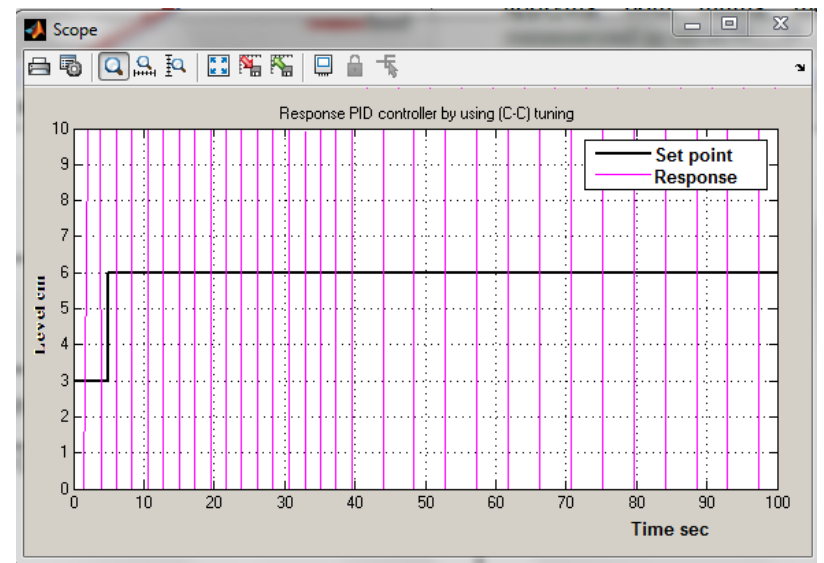

Figure 14 Simulation response of PID-controller by using (CC) tuning

\subsection{Performance Analysis of System}

In this section, P, PI and PID controller have been used to control the liquid level efficiently. The three parameters of the PID controller have been adjusted by applying (Z-N) and (C-C) tuning methods as summarized in Table 7. The performance of $\mathrm{P}, \mathrm{PI}$ and $\mathrm{PID}$ controller to step-change in set point of liquid level from ( 3 to $6 \%$ ) have been observed and applied in real-time. Figures 15,16 and 17 show the response of controllers in real-time. From the figures, we found that the Pl- controller has lower overshoot and minimum rise time.

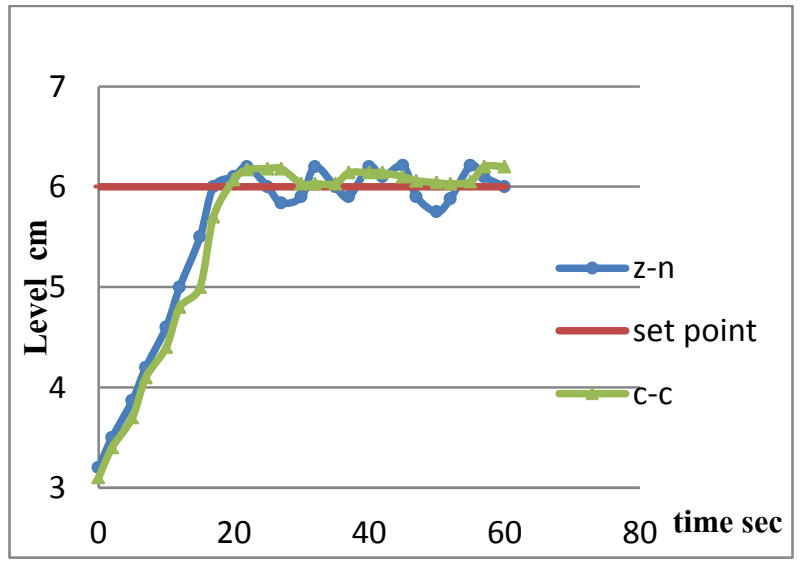

Figure 15 Real time response of P-controller by using (Z-N) and $(\mathrm{C}-\mathrm{C})$ tuning

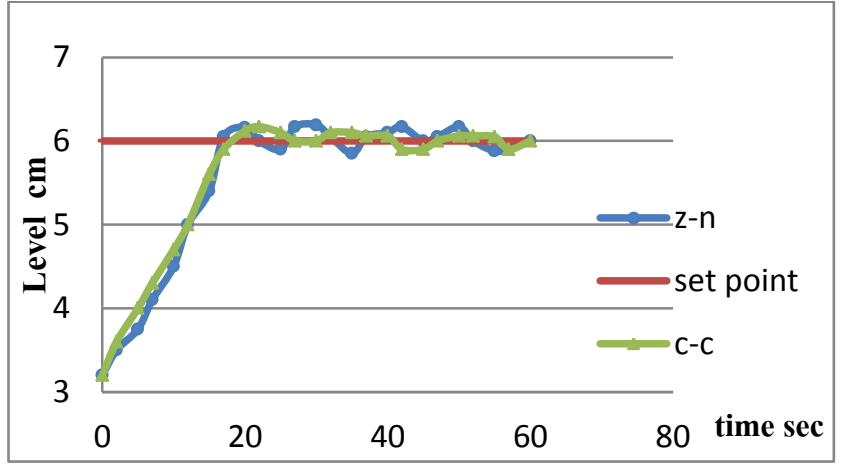

Figure 16 Real time response of PI-controller by using (Z-N) and $(\mathrm{C}-\mathrm{C})$ tuning

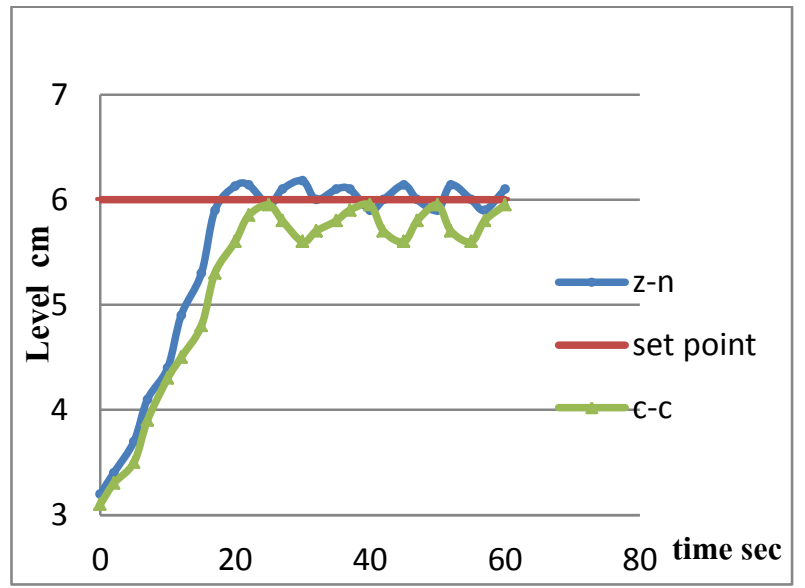

Figure 17 Real time response of PID-controller by using (Z-N) and $(\mathrm{C}-\mathrm{C})$ tuning 
The comparison between the Rise time, Settling time, and percentage overshoot for the controllers $\mathrm{P}, \mathrm{PI}$, and PID is shown in Table 8 . It is noted that the $\mathrm{Pl}$-controller provides more satisfactory performance with reference to rise time, settling time and percentage overshoot \% in comparison to the $\mathrm{P}$ and PID controller.

Table 8 Comparison of Performance Response between (ZN) and (C-C) Methods

\begin{tabular}{ccccccc}
\hline \multirow{2}{*}{$\begin{array}{c}\text { Tuning } \\
\text { rules }\end{array}$} & \multicolumn{3}{c}{$\begin{array}{c}\text { (Ziegler-Nichols) } \\
\text { Method }\end{array}$} & \multicolumn{3}{c}{$\begin{array}{c}\text { (Cohen-Coon) } \\
\text { Method }\end{array}$} \\
\cline { 2 - 7 } & $\mathrm{P}$ & $\mathrm{Pl}$ & $\mathrm{PID}$ & $\mathrm{P}$ & $\mathrm{Pl}$ & $\mathrm{PID}$ \\
\hline $\begin{array}{c}\text { Rise time } \\
\text { (sec) }\end{array}$ & 17 & 16 & 18 & 19 & 18 & 25 \\
$\begin{array}{c}\text { Settling } \\
\text { time (sec) } \\
\text { Overshoot } \\
\%(\mathbf{c m})\end{array}$ & $>80$ & 65 & $>80$ & $>80$ & $>80$ & $>80$ \\
\hline
\end{tabular}

The integral absolute error (IAE) and integral square error (ISE) are often used to evaluate the response of control system at different controller tuning methods as shown in Table 9. From the table, it is observed that Pl-controller with (Z-N) and (C-C) tuning has the lowest value of (IAE) and (ISE).

Table 9 Error Analysis for Different Tuning Methods

\begin{tabular}{ccccccc}
\hline \multirow{2}{*}{ Method } & \multicolumn{2}{c}{ P-Controller } & \multicolumn{2}{c}{ PI- Controller } & \multicolumn{2}{c}{ PID-Controller } \\
\cline { 2 - 7 } & IAE & ISE & IAE & ISE & IAE & ISE \\
\hline Z-N & 29.560 & 46.724 & 29.285 & 46.477 & 29.90 & 52.386 \\
C-C & 31.195 & 56.450 & 30.368 & 48.970 & 39.950 & 68.386 \\
\hline
\end{tabular}

\subsection{CONCLUSION}

In this study, PID Controller is implemented to control the liquid level in tank within the desire values. (Z-N) and (C-C) tuning methods were used to find controlling variables that were actually tested in the real time to find the efficiency of the controllers. The mathematical model of liquid level in the tank has been derived depending on the material balance and the transfer function was first order with a delay time.

$$
\mathrm{G}_{\mathrm{sys}}(\mathrm{s})=\frac{\mathrm{H}_{(\mathrm{s})}}{\mathrm{Q}_{\mathrm{i}(\mathrm{s})}}=\frac{\mathrm{Re}^{-\theta . s}}{(\tau \mathrm{s}+1)}
$$

MATLAB is used to test the controller's performance and then compare the results with those presented in the real time. From simulation results, it was found that $\mathrm{PI}$ controller has best performance and giving lower overshoot and less setting time. (IAE) and (ISE) values are calculated for tow tuning methods, and it is observed that (Z-N) method give good performance for PI-controller. Hence, we concluded that PI controller tuning with
(Z-N) method gives best response for the controlling of liquid level.

\section{Nomenclature}

$\mathrm{q}_{\mathrm{i}}$ : Water flow inlet $\left(\mathrm{cm}^{3} / \mathrm{sec}\right)$

qo : Water flow outlet $\left(\mathrm{cm}^{3} / \mathrm{sec}\right)$

$\mathrm{V}$ : Volume of water in the tank $\left(\mathrm{cm}^{3}\right)$

A : Area of tank $\left(\mathrm{cm}^{2}\right)$

$\mathrm{H}$ : Height of water in tank $(\mathrm{cm})$

$P_{\text {out }} \quad$ : Output signal from controller, psig.

$\mathrm{R} \quad$ : Process gain ( $\left.\mathrm{sec} / \mathrm{cm}^{2}\right)$

$\mathrm{KC} \quad$ : Proportional gain

$\mathrm{Ku} \quad$ : Ultimate gain.

Pu : Ultimate period (minutes per cycle)

e : Error (set point)-(measured variable).

\section{Greek Letters}

$\begin{array}{ll}\rho & : \text { Water density }\left(\mathrm{g} / \mathrm{cm}^{3}\right) \\ T_{1} & : \text { Integral time (minute) } \\ \text { TD } & \text { : Derivative time (minute) } \\ \theta & : \text { Time delay (minute) } \\ T & : \text { Time constant (minute) }\end{array}$

\section{Abbreviations}

P Proportional

PI : Proportional-Integral

PID : Proportional-Integral-Derivative

IAE : Integral Absolute Error

ISE : Integral Square Error

\section{Reference}

[1] Luyben, L. 1989. Process Modeling, Simulation, and Control for Chemical Engineer. New York: McGraw Hill, Inc.

[2] Rhodes, L. 1996. The Process Simulation Revolution: Thermo physical Property Needs and Concerns. Journal of Chemical and Engineering Data. 41:947-950.

[3] Donald, C., and Stevan, L. 2009. Process Systems Analysis and Control. New York: McGraw Hill, Inc.

[4] Ogunnaike, A. and Ray, H. 1994 Process Dynamics, Modeling and Control. New York: Oxford University Press, Inc.

[5] Qahtan, A. M., Amer, T. N., Maha, E., Layth T. and Omar, D. 2018. PID Temperature Control of Demineralized Water Tank. International Conference on Materials Engineering and Science, IOP Publishing. 454(2018): 012031

[6] Dale, S., Thomas, E. and Duncan, M. 2011. Process Dynamics and Control. John Wiley and Sons, Inc.

[7] Marlin, E. 2000. Process Control: Designing Processes and Control Systems for Dynamic Performance. McGraw-Hill.

[8] Brian, R. and Ben, B. 2006. Process Dynamics and Control, Modeling for Control and Prediction. Netherlands: John Wiley and Sons Ltd.

[9] Tyreus, D. and Luyben, L. 1992. Tuning of PI Controllers for Integrator/Dead Time Processes. Ind. Eng. Chem. Res. 31 (11): 2625-2628.

[10] Beza, G. 2016. Water Level Controlling System Using Pid Controller. International Journal of Applied Engineering Research. 11 (23): 11223-11227. 
[11] Vassilios, T., Sanjo, P., Matthew, S. and Truong, D. 2013. Modeling, Simulation and Control of Temperature and Level in a Multivariable Water Tank Process. International Journal of Engineering, Research and Development. 8(6): 01-11

[12] Mostafa, F. and Aboubaker, G. 2015. PID Controller Design for Two Tanks Liquid Level Control System Using Matlab. International Journal of Application or Innovation in Engineering and Management. 4(5).

[13] Yuli, W. 2018. Study of Double-holding Water Tank Liquid Level Control Base on Neural Networks PID Control. Advances in Intelligent Systems Research (AISR). 151.

[14] Philips, C. L. and Harbor, R. D. 1991. Feedback Control Systems. 2nd edition. Prentice-Hall.
[15] Astrom, K.J. and Hagglund, T. (1995). PID controllers: theory, design and tuning, Instrument Society of America.

[16] Power, H. M. and Simpson, R. J. 1978. Introduction to Dynamics and Control. McGraw-Hill.

[17] Araki, M. 2008. PID Control. Encyclopedia of Life Support Systems (EOLSS). 2(1): 26.

[18] Shinskey, F. G. 1996. Process Control SystemsApplication, Design and Tuning. 4th Edition. McGrawHill Inc.

[19] Ashish, T. 2002. Modern Control Design with MATLAB and Simulink. England: John Wiley and Sons.

[20] Leigh, J. R. 1987. Applied Control Theory. Revised 2nd edition. Peter Peregrinus Ltd. 